\title{
Respiratory Syncytial Virus Infection Reinforces Reflex Apnea in Young Lambs ${ }^{1}$
}

\author{
CARL LINDGREN, LIN JING, BARNEY GRAHAM, JENS GRÖGAARD, AND HÅKAN SUNDELL
}

Vanderbilt University School of Medicine, Departments of Pediatrics and Medicine,

Nashville, Tennessee 37232-2585

\begin{abstract}
To evaluate the effect of respiratory syncytial virus (RSV) infection on reflex apnea elicited by application of water on the laryngeal mucosa, 11 healthy, term lambs were chronically instrumented at 2 wk of age. Six lambs were inoculated with bovine RSV, and five lambs were mock-infected. The lambs were studied awake and unsedated before and 4, 8, 14, and $21 \mathrm{~d}$ after infection. RSV infection was associated with slight rhinorrhea and with moderately increased tracheal mucous discharge. There was an average increase of $0.5^{\circ} \mathrm{C}$ in body temperature. Arterial $\mathrm{pH}, \mathrm{PO}_{2}$, and $\mathrm{PCO}_{2}$ remained within the normal range. The ventilatory response to laryngeal chemostimulation measured as the percentage of decrease in ventilation from control was significantly $(p<0.05)$ larger among the infected animals when compared with controls on $\mathbf{4}$ and 8 . There were no differences in indices of respiratory drive (airway occlusion pressure and mean inspiratory flow), ventilatory response to hypoxia $(0.10$ fraction of inspired $\left.\mathrm{O}_{2}\right)$, or hypercarbia $(0.03$ fraction of inspired $\mathrm{O}_{2}$ ). We speculate that $\mathrm{RSV}$ infection alters the sensitivity of the laryngeal chemoreceptors so that a prolonged or even fatal apnea may result from stimulation of these receptors. These results may be relevant to the pathogenesis of sudden infant death syndrome associated with RSV infection. (Pediatr Res 31: 381-385, 1992)
\end{abstract}

\section{Abbreviations}

RSV, respiratory syncytial virus

BRSV, bovine respiratory syncytial virus

LCR, laryngeal chemoreflex

SIDS, sudden infant death syndrome

SLN, superior laryngeal nerve

$\mathrm{FiO}_{2}$, fraction of inspired oxygen

$\mathrm{FiCO}_{2}$, fraction of inspired carbon dioxide

BT, bovine turbinate

Epidemiologic studies have repeatedly demonstrated a number of variables affecting the incidence of SIDS. Characteristically, the peak incidence is between 2 and 4 mo of age. Prematurity, low birth weight, and maternal smoking are associated risk factors $(1,2)$. SIDS is known to peak during the cold and dark months of the year $(3,4)$, the time that corresponds to the annual peak prevalence of respiratory disease caused by RSV. RSV is a negative-strand RNA virus in the family Paramyxoviridae. It is

Received May 28, 1991; accepted December 4, 1991.

Correspondence: Håkan W. Sundell, M.D., Vanderbilt University School of Medicine, Department of Pediatrics, Nashville, TN 37232-2585.

Supported by grants from the National Institutes of Health (HD 22712 and $\mathrm{HL}$

14214). C.L. was partly supported by the Swedish Medical Research Council.

Presented in part at the annual meeting of the Society for Pediatric Research the most common etiology of serious respiratory tract infection in infants and typically causes bronchiolitis, which is most severe during the first 6 mo of life. Prolonged apnea is believed to be a crucial part of the pathophysiology of SIDS (5). RSV is known to cause apnea among approximately $20 \%$ of hospitalized infants under $1 \mathrm{y}$ of age $(6,7)$. Prematurity and young age are risk factors for the development of apnea during this infection. The mechanism of RSV-associated apnea remains unclear, but the observation that apnea is more common among young infants suggests that RSV infection interferes with some aspect of respiration determined by maturation.

Previous animal and human studies have shown that stimulation of laryngeal chemoreceptors by a variety of solutions or electrical stimulation of the SLN produces apnea, hypertension, bradycardia, and redistribution of blood flow $(8,9)$. This reflex response is attenuated with increasing age. Recent observations have demonstrated similarities between apnea of prematurity, LCR apnea, and RSV-associated apnea, i.e. central apnea, obstructed breaths, swallows, and coughs, suggesting a common causal mechanism involving the laryngeal chemoreceptors and/ or their afferent pathways in the SLN (10).

Respiratory viruses, especially RSV, have been detected postmortem with higher frequency in SIDS victims compared with age-matched controls dying from other causes (11-13). An intriguing observation is that many SIDS victims have a history of a mild respiratory tract infection before death, although not severe enough to be a primary explanation for the fatal outcome. Despite much circumstantial evidence, a direct link between respiratory tract infections and SIDS has not been established, possibly because such infections are very common during the 1st y of life yet SIDS is uncommon.

The aim of this study was to evaluate the effect of experimental RSV infection on the LCR apnea response elicited by application of water onto the laryngeal mucosa and to investigate respiratory control mechanisms that may influence the magnitude of this response.

\section{MATERIALS AND METHODS}

Animal care and instrumentation. Eleven term, healthy lambs of Suffolk or Dorset breeds were chronically instrumented at 2 wk of age with venous and arterial catheters and a low tracheostomy. Continuity of the rostral and distal part of the trachea was established by a prosthesis consisting of a piece of endotracheal tube (Portex, Keene, NH; 4.5-6.5), which allowed the lambs to breath normally when not being studied. Antibiotics (gentamicin $4-5 \mathrm{mg} / \mathrm{kg} / \mathrm{d}$ and carbenicillin $75 \mathrm{mg} / \mathrm{kg} / \mathrm{d}$ ) were given daily from time of instrumentation until the lambs were killed. No lamb showed clinical signs of bacterial infection. The lambs were housed with the ewe and nursed ad libitum. After surgery, the lambs were allowed at least $24 \mathrm{~h}$ to recover before the first study and inoculation with virus or control preparation. At the time of the study, the prosthesis was removed, and through the tracheostoma a biluminal Foley catheter was inserted and 
directed upward, with the tip of the catheter placed just below the vocal cords. A tight-fitting endotracheal tube (Portex 5.58.0) was inserted and directed toward the lungs. The balloons of the endotracheal tube and the Foley catheters were inflated. Position and function of the Foley catheter were tested by infusing $1 \mathrm{~mL}$ of normal saline through the catheter onto the laryngeal mucosa, which resulted in a short period of apnea and swallowing. The endotracheal tube was connected to a pneumotachograph (Hewlett-Packard 21071-60040, Waltham, MA) and further to a Baby Bird ventilator (Bird Corp., Palm Springs, CA), supplying a continuous positive airway pressure of $4 \mathrm{~cm}$ of water to compensate for reduced upper airway tone due to endotracheal intubation. Statham pressure transducers $(\mathrm{P} 23 \mathrm{Gg}$; Gould-Statham, Oxnard, CA) were used for blood pressure and heart rate measurements. All recordings were made on an eightchannel Hewlett-Packard 8800 S cardiovascular recording system. Blood gas analyses were performed with the model 158 instrument made by Corning Medical, Ciba Corning Diagnostic Corp., Medfield, MA. The lambs were studied fully awake and unsedated, standing in an Alice-King sling (Alice King Chatham Medical Arts, Hawthorne, CA) with the ambient temperature ranging from $21-23^{\circ} \mathrm{C}$.

The research protocol was approved by the Vanderbilt University Animal Care Committee.

LCR stimulation. Before the LCR stimulations, a 1-h baseline recording was made of ventilation, blood pressure, and heart rate to detect any spontaneous apnea. When the lambs were judged to be awake and relaxed and had normal regular breathing, a 30$s$ baseline period was recorded, the airflow integrator was manually reset, and $1 \mathrm{~mL}$ of distilled water at room temperature was infused during $5 \mathrm{~s}$ through the Foley catheter. Three LCR stimulations were performed, at least $5 \mathrm{~min}$ apart, allowing the animals to recover fully between stimulations. The mean effect on respiration of these three stimulations was calculated.

Ventilatory response to LCR stimulation. The effect of LCR stimulation on ventilation was assessed in two ways: 1) ventilatory response (percentage of decrease in ventilation volume during $30 \mathrm{~s}$ after stimulation compared with the 30 -s baseline period), and 2) recovery time (time from onset of stimulus to reestablished regular breathing for a period of at least $10 \mathrm{~s}$ ). Studies were performed before the lambs were inoculated and were repeated $4,8,14$, and $21 \mathrm{~d}$ after inoculation with RSV virus or control preparations.

Heart rate response to $L C R$ stimulation. Heart rate was calculated from the blood pressure tracing during the last $5 \mathrm{~s}$ preceding the stimulus ( $1 \mathrm{~mL}$ of water during $5 \mathrm{~s}$ ) and was compared with the rate during the $5 \mathrm{~s}$ after the termination of the stimulus. The response was expressed as the percentage of change.

Respiratory drive. Airway occlusion pressure and mean inspiratory flow were used as indices of respiratory drive. To determine airway occlusion pressure, the ventilator was disconnected. Airway pressure was measured through a small polyethylene catheter (inner diameter $=0.71 \mathrm{~mm}$ ) inserted into the endotracheal tube. Airway occlusion pressure was measured $0.1 \mathrm{~s}$ after the onset of inspiration using a recorder speed of $50 \mathrm{~mm} / \mathrm{s}$. A series of 10 occlusions was made at end expiration, no more frequently than every 4th breath, and an average was calculated for each study. Mean inspiratory flow was measured as the ratio of tidal volume and inspiratory time. Twenty breaths were used to calculate an average volume for each study.

Hyperoxia and hypercarbia tests. To evaluate peripheral chemoreceptors, the response to $0.10 \mathrm{FiO}_{2}$ was studied. After a 3-min baseline period, $\mathrm{FiO}_{2}$ was changed, without disturbing the lamb, from 0.21 to 0.10 using a blender (Bird High Flow Oxygen Blender, model 2900; Bird Corp.). The 1st min after the change in $\mathrm{FiO}_{2}$ was disregarded because of a time lag for $\mathrm{FiO}_{2}$ change in the respiratory circuit. The ventilatory response to hypoxia was expressed as the percentage of change in minute ventilation from baseline during the 1 st, 5 th, 10 th, and 15 th $\min$. The response to $0.03 \mathrm{FiCO}_{2}$ mixed with $0.25 \mathrm{FiO}_{2}$ was used to evaluate central chemoreceptors. Minute ventilation was measured during a 3min baseline period and during the 10th min after the abrupt change in $\mathrm{FiCO}_{2}$. Arterial $\mathrm{PCO}_{2}$ was determined during the baseline period and during the 10th min of hypercarbia.

Virus stock and cell culture. BRSV stock strain A51908 (no. VR794) was obtained from American Type Culture Collection (Rockville, MD) and cultivated in BT cells (generously provided by Tennessee Animal Diagnostic Laboratory, Ellington Agricultural Center, Nashville, TN) grown in 10\% EMEM (Eagle's minimal essential media containing $10 \% \mathrm{FCS}$, penicllin, gentamicin, and amphotericin B). The serum lot was screened for the presence of neutralizing antibody to BRSV and was negative. The presence of mycoplasma in the cells was excluded by RNA hybridization (Gen-Probe, San Diego, CA). Virus stock was prepared by triple plaque purification on MDBK cells (American Type Culture Collection, no. CCL22) to make master stock, then working stocks were made by infecting subconfluent BT cells. When cells demonstrated diffuse syncytial formation, the cell layer was scraped into the media, and the suspension was sonicated for $25 \mathrm{~s}$ before quick-freezing in dry ice/acetone. Viral stocks were frozen at $-70^{\circ} \mathrm{C}$, and each $2-\mathrm{mL}$ aliquot was briefly sonicated before use. A mock-infected cell preparation was made by the identical method for inoculation of control lambs. The BRSV stock used for infection had a titer of $5 \times 10^{5}$ plaqueforming units $/ \mathrm{mL}$.

Virus isolation, plaque assays, and neutralization assays. Virus isolation was performed by taking a nasopharyngeal swab from each nostril and directly inoculating it into $2 \mathrm{~mL}$ of $10 \%$ EMEM. Plaque assays were performed using $0.1 \mathrm{~mL}$ of inoculum and 10 -fold dilutions on subconfluent BT cells under a $0.75 \%$ methylcellulose in $10 \%$ EMEM overlay. When plaques were well formed, the plates were fixed with $10 \%$ buffered formalin and stained with hematoxylin and eosin. Neutralization assays were performed on serial serum samples obtained 3 to $6 \mathrm{wk}$ after inoculation by mixing $100 \mathrm{~mL}$ of heat-inactivated $\left(56^{\circ} \mathrm{C}\right.$ for 30 min) serum dilutions with $100 \mathrm{~mL}$ of a titered pool of BRSV for $60 \mathrm{~min}$ at $25^{\circ} \mathrm{C}$. Fifty $\mathrm{mL}$ of each suspension was added in triplicate to BT cells. Plaque numbers were compared with those derived from a PBS control, and the neutralization titer was determined by linear regression analysis and reported as the $\log _{2}$ reciprocal serum dilution that resulted in $50 \%$ plaque reduction.

Virus inoculation. Undiluted BRSV stock or the control preparation was delivered in a tuberculin syringe. Each lamb received $4 \mathrm{~mL}$ via the tracheostomy site and $2 \mathrm{~mL}$ in each nostril.

Statistics. Statistical significance $(p<0.05)$ between groups was assessed using the Mann-Whitney U-test.

\section{RESULTS}

Clinical. None of the lambs showed any signs of severe respiratory disease, nor were there any signs of superimposed bacterial infection observed by clinical observation. The lambs had a normal weight gain. Slight rhinorrhea and moderately increased tracheal mucous discharge were present among the infected lambs. No rales or rhonchi were heard by listening to the lungs. Arterial $\mathrm{pH}, \mathrm{PO}_{2}$, and $\mathrm{PCO}_{2}$ showed values within the normal range and did not differ between the groups. Chest radiographs were not obtained. Rectal temperature and white blood cell count were checked daily during the first $8 \mathrm{~d}$ after infection and were similar between groups, although the study group showed a trend toward slightly elevated and more unstable rectal temperature.

Spontaneous apnea. Only one of the six infected lambs had spontaneous apnea during the 1-h baseline recording on $\mathrm{d} 4$, with breathing pauses lasting more than $4 \mathrm{~s}$ and a total time of apnea accounting for $2.6 \%$ of recorded time. None of the mockinfected lambs had spontaneous apnea.

Ventilatory response to LCR stimulation. Five of six infected lambs had increased ventilatory response to laryngeal water stimulation, i.e. more pronounced decreased ventilation, on the 
4 th or 8th d after inoculation when compared with either themselves before inoculation or uninfected controls (Fig. 1). All of the control lambs showed a gradual decrease in response over time. There were large individual differences in response to stimulation among infected lambs, suggesting a biologic variation in susceptibility to LCR stimulation during RSV infection. In contrast, the individual variation within the control group was smaller. Statistically significant differences were observed between groups on the 4 th and 8 th d after inoculation (Table 1).

Recovery time after LCR stimulation. Time elapsed after onset of laryngeal water stimulation until onset of regular breathing was significantly prolonged in the infected group on the 4th and 8th d after inoculation when compared with the control group (Fig. 2, Table 1). All lambs in both groups had apnea after LCR stimulation. The uninfected lambs usually had only one short period of apnea, after which regular breathing rapidly resumed. The infected lambs not only had longer initial apnea but also frequently had repeated periods of apnea interposed by irregular breathing until they fully recovered (Fig. 3).

Heart rate response to $L C R$ stimulation. A decrease in heart rate was consistently seen during the LCR response to water stimulation. The heart rate response (\% decrease from baseline $5-10 \mathrm{~s}$ after onset of stimulus) increased slightly from $32 \pm 6 \%$ before RSV inoculation to $37 \pm 7 \%$ on the 4 th $d$ and $34 \pm 7 \%$ on the 8th d after inoculation and decreased thereafter to $17 \pm$ $5 \%$ on the 21 st $\mathrm{d}$. There was a gradual decrease from $33 \pm 7 \%$ on the day of control inoculation to $18 \pm 3 \%$ on the $21 \mathrm{st} \mathrm{d}$ in the control lambs. There were no significant differences between groups.

Airway occlusion pressure and mean inspiratory flow. Airway occlusion pressure and the mean inspiratory flow were similar in the two groups before and on the 4th and 8th d after inoculation, which corresponds to the time period of increased apnea response to laryngeal water stimulation.

Ventilatory response to hypoxia and hypercarbia. The ventilatory response during the 1 st $\mathrm{min}$ of hypoxia $\left(0.10 \mathrm{FiO}_{2}\right)$ did not change significantly over time and was not significantly different in the two groups before and on the 4th and 8th $\mathrm{d}$ after inoculation, nor was the ventilatory response at 5,10 , and 15 min of $0.10 \mathrm{FiO}_{2}$ significantly altered. The response to inhaled $\mathrm{CO}_{2}\left(0.03 \mathrm{FiCO}_{2}\right)$ expressed as the slope of the $\mathrm{CO}_{2}$ response curve $(\mathrm{mL} / \mathrm{min} / \mathrm{kg} / \mathrm{kPa})$ was not significantly different over time or between groups.

Virology. BRSV was isolated from one of the six infected lambs on d 5 after inoculation. Serologic testing showed that three of the six lambs inoculated with RSV had a rise in neutralization antibody titers 3 to $6 \mathrm{wk}$ after inoculation, whereas the titers in the other three remained unchanged. Neutralization antibody titers in all five of the control lambs either remained unchanged or declined.

\section{DISCUSSION}

This study showed that the laryngeal chemoreflex apnea response is markedly exaggerated during BRSV infection in young lambs, yet spontaneous apnea was only seen in one lamb. These lambs showed no or only mild symptoms of RSV infection and should, therefore, represent a suitable animal model in which to study infection-induced apnea, which is thought to play a role in the death of some SIDS victims. There was a substantial variability in the reflex apnea response in these lambs, which is analogous with reports showing that only a minority of RSVinfected infants exhibit apnea and that there is no correlation between apnea and the clinical severity of the disease $(6,7,14)$. The variability may also relate to the difficulty of establishing a virulent infection in the experimental setting.

Although some risk groups for SIDS now are recognized, the majority of SIDS victims do not belong to a defined risk group (2). We speculate that among seemingly healthy infants with no known risk factors for SIDS there exists a subgroup of infants with increased laryngeal chemoreceptor sensitivity who, when infected with or incubating RSV and possibly other respiratory viruses, will exhibit spontaneous apnea from which they may fail to recover.

Although documented (15), RSV infection is rare during the first 4 wk of life, as is SIDS. An immunologic protection during the neonatal period, therefore, seems plausible. Passive transfer of maternal $\mathrm{IgG}$ could theoretically provide some protection. IgA is abundant in breast milk and could also be potentially beneficial. A lower risk for SIDS is reported for breast-fed infants when compared with formula-fed infants (1). SIDS victims who die in conjunction with a respiratory tract infection tend to be older than those who die without any signs of infectious disease involving the airways $(13,16)$. Also, seasonal variation, with a peak during the winter months, is more evident among older $(>3 \mathrm{mo}$ ) than younger infants dying of SIDS (4). However, other data indicate that apnea during RSV infection is more common in infants less than 2 mo of age (17). Although there is a clinical association of RSV with apnea, the pathogenesis is undefined.

It is possible that cytopathic effects on laryngeal epithelium could change the sensitivity of receptors involved in reflex apnea. Studies of electrophysiologic properties of the isolated trachea from RSV-infected cotton rats have shown significant changes in active and passive ion flows, resulting in a marked decrease
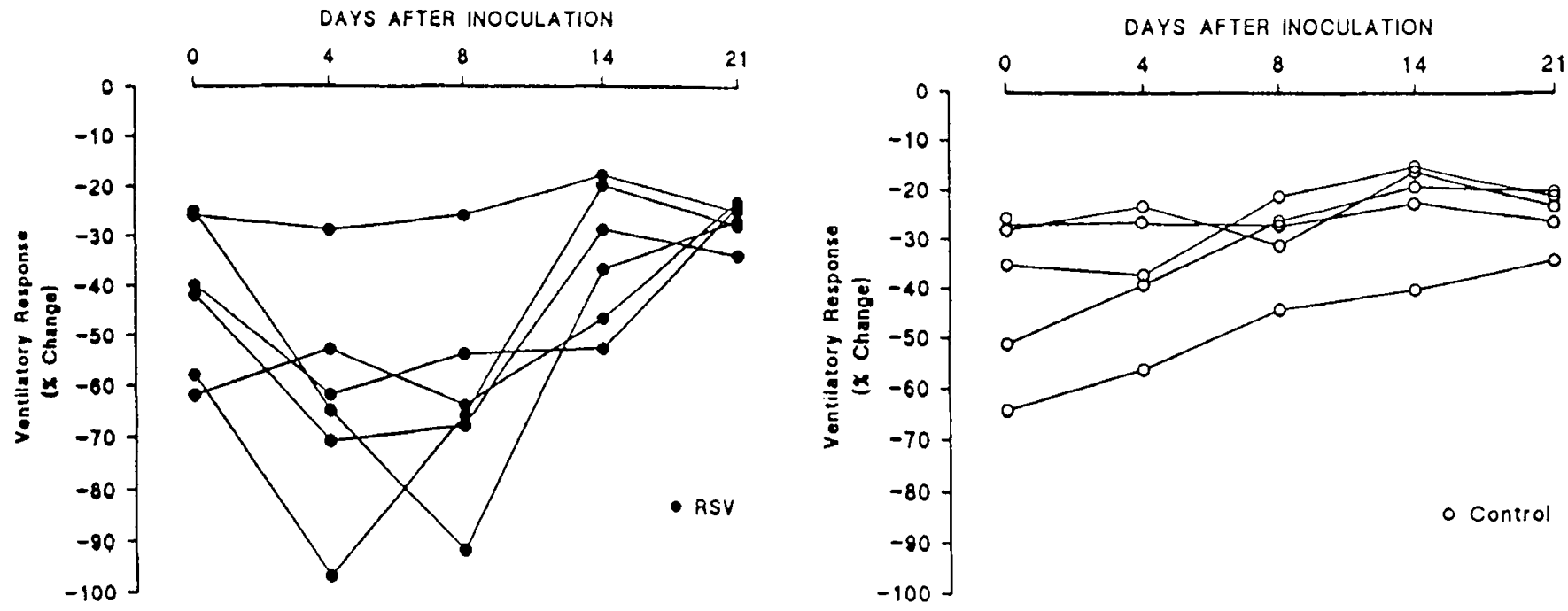

Fig. 1. Ventilatory response to laryngeal water stimulation in six lambs inoculated with RSV and five mock-infected control lambs. 
Table 1. Response to laryngeal water stimulation*

\begin{tabular}{|c|c|c|c|c|c|}
\hline \multirow{2}{*}{$\begin{array}{l}\text { Experimental } \\
\text { group }\end{array}$} & \multicolumn{5}{|c|}{ Days after inoculation } \\
\hline & 0 & 4 & 8 & 14 & 21 \\
\hline \multicolumn{6}{|c|}{ Ventilatory response (\% decrease) } \\
\hline RSV & $42 \pm 6$ & $63 \pm 10 \dagger$ & $62 \pm 9 \dagger$ & $34 \pm 6$ & $27 \pm 2$ \\
\hline Control & $41 \pm 7$ & $36 \pm 6$ & $30 \pm 4$ & $23 \pm 5$ & $25 \pm 3$ \\
\hline \multicolumn{6}{|l|}{ Recovery time (s) } \\
\hline RSV & $24 \pm 3$ & $47 \pm 9 \dagger$ & $54 \pm 8 \dagger$ & $35 \pm 15$ & $39 \pm 3$ \\
\hline Control & $21 \pm 6$ & $16 \pm 4$ & $14 \pm 4$ & $14 \pm 3$ & $18 \pm 4$ \\
\hline
\end{tabular}

* Values are means \pm SEM.

$\dagger$ Statistically significant differences between groups, $p<0.05$.
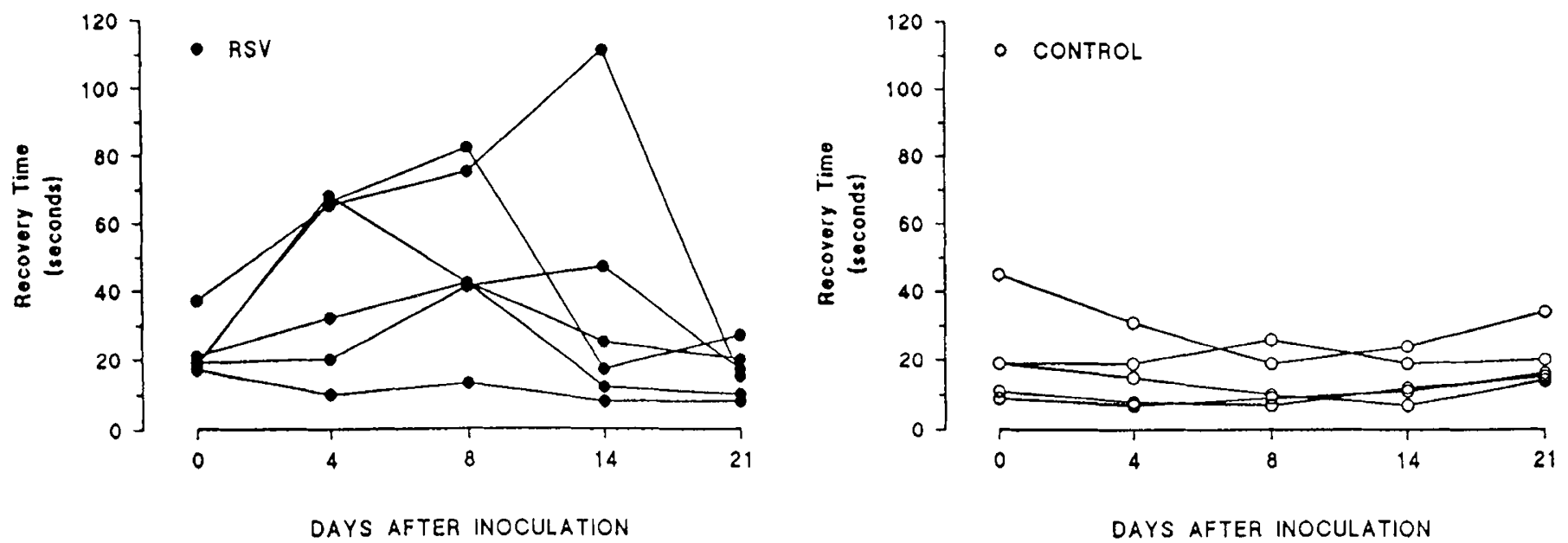

Fig. 2. Time from onset of stimulus to reestablished regular breathing (recovery time) in six lambs inoculated with RSV and five mock-infected control lambs.

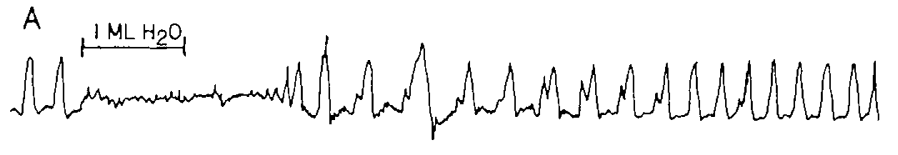

$\mathrm{B}$

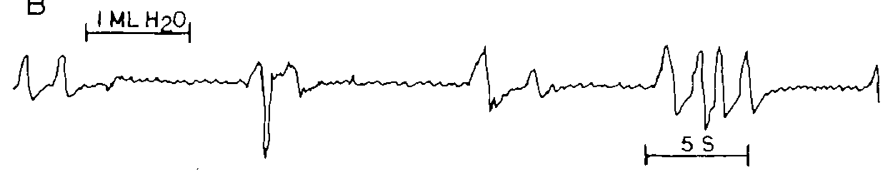

Fig. 3. Air flow signals from a 3-wk-old lamb showing the response to laryngeal chemostimulation before $(A)$ and $8 \mathrm{~d}$ after $(B)$ inoculation with RSV.

in short-circuit current and an increase in tissue resistance (18). These changes were attributed to a decrease in chloride secretion and restriction to sodium and chloride through the paracellular pathways in the RSV-infected tracheas. If present in the laryngeal mucosa as well, such alterations in the ionic and electrophysiologic environment may influence the sensitivity of the laryngeal chemoreceptors and may be an explanation for our findings.

Two lambs had antibodies against RSV before inoculation and yet showed an RSV effect on the LCR response. McNulty et al. (19) have demonstrated that preexisting, maternally derived antibody to BRSV does not protect calves from experimental BRSV infection (19). Experimental RSV infection in bovine models has been reported to cause ultrastructural lesions in ciliated and nonciliated bronchiolar epithelium. Hyperplasia of basal epithelial cells and loss of normal epithelium in calves occurred between $\mathrm{d} 5$ and 7 , with airway epithelium being repaired by $\mathrm{d} 10$ (20). The occurrence of these epithelial changes correlates with the time frame in which reflex apnea was enhanced in our study. There is evidence that some BRSV strains are at least antigeni- cally related to ovine RSV (21) and that BRSV can be used in experimental infection of lambs (22). Bronchiolitis and interstitial pneumonia inducing modest pathologic changes have been described in BRSV infection of lambs $(23,24)$. Mild clinical respiratory tract disease associated with histologic evidence of bronchitis and bronchiolitis has been described after repeated inoculations with ovine RSV (25). Subclinical illness associated with short-lived changes in lung function has recently been reported after a single inoculation with ovine RSV in 2-wk-old lambs (26). These studies are comparable with our showing a subclinical or mild infection. Virus was difficult to isolate from nasopharyngeal swabs in those studies, which is analogous to the low rate of virus isolation in our study. We, therefore, believe that the lambs in our study developed an RSV infection, although this could not be proven consistently by serologic or virologic techniques.

Our results do not answer the question of how laryngeal chemostimulation during RSV infection results in more severe and prolonged apnea. Although the location of RSV infection is limited to the respiratory epithelium and these results indicate that there are no demonstrable effects on indices of respiratory drive or central and peripheral chemoreceptor function, it is possible that the central poststimulus reflex-induced mechanism (27) is altered by inflammatory mediators. Interestingly, muramyl dipeptide acting through IL-1 has recently been proposed to exert a central depressing effect during infection (28). Further delineation of the mechanism for RSV-induced apnea and ongoing work to find methods to prevent RSV infection will be important components of the objective to eliminate SIDS.

In conclusion, this study has shown that young lambs inoculated with BRSV develop a mild or subclinical illness that is associated with an increased apnea response to laryngeal water stimulation. The ventilatory response to acute hypoxia or hypercarbia was not affected, demonstrating that the RSV infection did not alter peripheral or central chemoreceptor function. Air- 
way occlusion pressure and mean inspiratory flow measurements were unchanged, indicating that central respiratory drive was not influenced. Because we did not observe any RSV-induced generalized effects on respiratory control mechanisms, we speculate that RSV infection alters the sensitivity of the laryngeal chemoreceptors locally, so that a prolonged or even fatal apnea may result from stimulation of these receptors. These results may be relevant to the pathogenesis of SIDS associated with RSV infection.

Acknowledgments. The authors thank Patricia Minton, R.N., Stanley Poole, and Rao Gaddipati for skilled technical advice and Donna Staed for typing the manuscript.

\section{REFERENCES}

1. Kraus J, Greenland S, Bulterys M 1989 Risk factors for sudden infant death syndrome in the US collaborative perinatal project. Int J Epidemiol 18:113119

2. Bentele K, Albani M 1988 Are there tests predictive for prolonged apnea and SIDS? Acta Paediatr Scand [Suppl]342

3. Peterson D, Sabotta E, Strickland D 1988 Sudden infant death syndrome in epidemiologic perspective: etiologic implication of variation with season of the year. Ann NY Acad Sci 533:6-12

4. Beal S 1978 Seasonal variation in sudden infant death syndrome. Lancet $1: 1257$

5. Steinschneider A 1972 Prolonged apnea and the sudden infant death syndrome: clinical and laboratory observations. Pediatrics 50:646-654

6. Bruhn F, Mokrohisky S, Mclntosh K 1977 Apnea associated with respiratory syncytial virus infection in young infants. J Pediatr 90:382-386

7. Church N, Anas N, Hall C, Brooks J 1984 Respiratory syncytial virus-related apnea in infants (demographics and outcome). Am J Dis Child 138:247-250

8. Johnson P, Salisbury DM, Storey AT 1975 Apnea induced by stimulation of sensory receptors in the larynx. In: Bosma JF, Showacre J (eds) Development of Upper Respiratory Anatomy and Function. DHEW Publication (NIH) 75-941, Washington, DC, pp 160-183

9. Grogaard J, Lindstrom D, Stahlman MT, Marchal F, Sundell H 1982 The cardiovascular response to laryngeal water administration in young lambs. $\mathbf{J}$ Dev Physiol 4:353-370

10. Pickens D, Schefft G, Storch G. Thach B 1989 Characterization of prolonged apneic episodes associated with respiratory syncytial virus infection. Pediatr Pulmonol 6:195-201

11. Ogra PL, Ogra SS, Coppola RP 1975 Secretory component and sudden-infantdeath syndrome. Lancet 2:387-390

12. Scott D, Gardner P, McQuillin J, Stanton A, Downham M 1978 Respiratory viruses and cot death. Br Med J 2:12-13

13. Williams A, Uren E, Bretherton L 1984 Respiratory viruses and sudden infant death. Br Med J 288:1491-1493

14. Anas N, Boettrich C, Hall C, Brooks J 1982 The association of apnea and respiratory syncytial virus infection in infants. $\mathrm{J}$ Pediatr 101:65-68

15. Hall BC, Kopelman AE, Douglas RG, Geiman JM, Meacher MP 1979 Neonatal respiratory syncytial virus infection. N Engl J Med 300:393-396

16. Steinschneider A 1977 Nasopharyngitis and the sudden infant death syndrome. Pediatrics 60:531-533

17. Colditz P, Henry R, DeSilva L 1982 Apnoea and bronchiolitis due to respiratory syncytial virus. Aust Paediatr J 18:53-54

18. Cloutier MM, Wong D, Ogra PL 1989 Respiratory syncytial virus alters electrophysiologic properties in cotton rat airway epithelium. Pediatr Pulmonol 6:164-168

19. McNulty MS, Bryson DG. Allan GM 1983 Experimental respiratory syncytial virus pneumonia in young calves: microbiologic and immunofluorescent findings. Am J Vet Res 44:1656-1659

20. Castleman WL, Lay JC, Chandkler SK, Slauson DO 1985 Experimental bovine respiratory syncytial virus infection in conventional calves: light microscopic lesions, microbiology, and studies on lavaged lung cells. Am J Vet Res 46:547-553

21. Adair BM, McFerran JB 1987 Differences in fluorescent antibody staining of bovine respiratory syncytial virus-infected cells by bovine and bovine sera. Vet Microbiol 13:87-91

22. Lehmkuhl HD, Cutlip RC 1979 Experimentally induced respiratory syncytial viral infection in lambs. Am $J$ Vet Res 40:512-514

23. Trigo FJ, Breeze RG, Evermann JF, Gallina AM 1984 Pathogenesis of experimental bovine respiratory syncytial virus infection in sheep. Am J Vet Res 45:1663-1670

24. Cutlip RC, Lehmkuhl HD 1979 Lesions in lambs experimentally infected with bovine respiratory syncytial virus. Am J Vet Res 40:1479-1482

25. Bryson DG, Evermann JF, Liggitt HD, Foreyt WJ, Breeze RG 1988 Studies on the pathogenesis and interspecies transmission of respiratory syncytial virus isolated from sheep. Am J Vet Res 49:1424-1430

26. Wagner MH, Evermann JF, Gaskin J, McNicol K. Small P, Atecenko AA 1991 Subacute effects of respiratory syncytial virus infection on lung function in lambs. Pediatr Pulmonol 11:56-64

27. Lawson EE 1981 Prolonged central respiratory inhibition following reflexinduced apnea. J Appl Physiol 50:874-879

28. Gunteroth W 1989 Interluekin-1 as intermediary causing prolonged sleep apnea and SIDS during respiratory infections. Med Hypotheses 28:121-123 